\title{
The undernutrition conundrum in India: current scenario and the way forward
}

\author{
K. K. Asha*, Suseela Mathew, M. M. Prasad and C. N. Ravishankar
}

In India, nutrient-deficient diets are a fact of everyday life for millions of people, and the largest undernourished population in the world lives in our country. Several factors are responsible for the current serious levels of malnutrition seen in the country, some of which are inadequate maternal nutritional status, unpredictable lactation behaviour, inappropriate infant and young children feeding practices, lack of women's education, and scant regard for sanitation. High levels of child malnutrition potentially result in poor physical growth, recurrent childhood illnesses that further impede development, low cognitive skills and educational attainment, and diminished productivity in adult years, thus impeding socio-economic development of the country. Though several government programmes are in place, there is lack of effective use of nutritional data generated and knowledge gained across studies to address the multifaceted problem of undernutrition. The current grave circumstances of undernutrition in India emphasize on the urgent need to take appropriate actions to improve the nutrition of its population so as to enable the country to meet its Agenda of Sustainable Development Goals by 2030.

Keywords: Child nutrition indicators, global nutrition targets, Sustainable Development Goals, undernutrition.

\section{Undernutrition in India}

THE World Health Organization (WHO), Geneva, defines undernutrition as a state arising out of inadequate nutrition caused by either consumption of far less calories than recommended, or by significantly lower intake of nutrients vital for growth and development ${ }^{1}$. Optimum growth and overall development of an individual, including his/her socio-economic ranking are an outcome of interplay of maternal, infant and childhood nutrition. While malnutrition in adults is assessed by body mass index (BMI) measurements, in children under-5, the three WHO standards of nutritional indices, viz. weight for age, height for age and weight for height are used ${ }^{2}$.

Nearly 200 million or $15 \%$ of India's population is undernourished according to estimates made by $\mathrm{FAO}^{3}$. Despite India being the fastest growing economy ${ }^{4}$, having surpassed China in the last couple of years, undernutrition among its population, especially child undernutrition is a persistent challenge. Adequate maternal, infant and childhood nutrition determine the overall physical and mental development of an individual. Underweightlower weight for age, stunting - lower height for age and wasting-lower weight for height are the WHO-

The authors are in the ICAR-Central Institute of Fisheries Technology, Matsyapuri PO, Cochin 682 029, India.

*For correspondence. (e-mail: asha.santhosh5@gmail.com) prescribed nutritional indices for assessment of child undernutrition. In 2019, India found itself in an unenviable position, having been ranked a lowly 102 among 117 nations by the Global Hunger Index based on the indices of stunting, wasting, underweight and mortality among children under-5 years of age, in addition to other parameters ${ }^{5}$. Statistics reveal how India continues to reel under the burden of undernutrition among its children under-5, despite being home to one of the world's largest flagship nutrition programmes, the Integrated Child Development Services (ICDS) focusing on nutrition for children under-5, instituted as early as in 1975 (ref. 6) and several others at the national and regional levels, introduced subsequently. In 2017, prevalence of stunting among children under-5 was about $38 \%$ while wasting and underweight children accounted for about $15 \%$ and $33 \%$ respectively, which were at a higher average prevalence than that of Sub-Saharan Africa?

\section{Undernutrition in India: causes and way forward}

Why is India home to the largest number of malnourished children in the world?

\section{Primary causes of undernutrition}

The basic causative factors contributing to undernutrition are poverty, food insecurity and illiteracy. Poverty, food 
insecurity and undernutrition coexist, as the poor are more likely to lack access to nutritionally adequate and micronutrient-rich food leading to poor nutrition outcomes. Since India has the grave distinction of having one of the world's largest female illiteracies, making progress in improving maternal and child nutrition outcomes is painfully slow ${ }^{8}$.

\section{Intergenerational concern}

It is necessary to address undernutrition from an intergenerational perspective. Pregnancies among undernourished anaemic adolescent girls are common, who are further exposed to poor nutrition and postnatal healthcare? Children born to these mothers grow up to be stunted and underweight adolescents having been fed poorly and raised in unhygienic conditions with no healthcare provisions. This cycle is repeated over and again across generations, resulting in cohorts of undernourished populations.

\section{Role of education}

The Chan School of Public Health, Massachusetts, USA lists the lack of education of mothers among the top five risk factors for child undernutrition in India ${ }^{10}$. Studies have indisputably correlated low levels of maternal education with high stunting and underweight prevalence among Indian children ${ }^{10}$. Educated women make informed choices, are aware of hygiene and sanitation, have better access to antenatal care which positively alters delivery outcomes, increases infant birth weights, cuts stunting rates and reduces the occurrence of underweight children below five years of age.

\section{Idiosyncratic traits of the Indian society}

Of the many regressive traits that plague the Indian society, the all-pervasive caste and gender-based inequalities are in the forefront which have a significant negative impact on nutritional status of the population ${ }^{11}$. The low levels of women's participation in domestic decision-making and redundant social mindsets have major adverse effects on maternal and child nutrition outcomes.

\section{Inequitable distribution of resources}

Currently, there is a skewed pattern of allocation of resources, both physical and financial among communities, placing certain sections of the society at a disadvantage. Undernutrition rates among tribal people across India have remained exceptionally high. The National Family Health Survey (NFHS)-4, International Institute of Population Science (IIPS), Mumbai report states that $44 \%$ of tribal children under five years of age are stunted, $45 \%$ are underweight and $27 \%$ are wasted ${ }^{12}$. While it is widely understood that undernutrition stems from several causes, tribal populations are subject to neglect and are plagued with additional concerns. Largely, these are issues like geographical seclusion, cultural disparities, inadequate attention by the state on development processes, inadequate access to public amenities and the like. Additional intensive efforts are needed to help these deprived communities to overcome the challenges and improve their access to nutrition-related sectors, so that the alarmingly high rates of undernutrition can be curbed.

\section{Policies and programmes}

Recognizing the enormous costs of undernutrition in terms of lost national productivity and economic growth, India has put in place several legislative policies and programmes over the years. Some of the notable ones are mentioned here: the Infant Milk Substitutes, Feeding Bottles and Infant Foods, the National Nutrition Policy 1993, the National Health Policy 2002, the National Food Security Act 2013, the National Policy for Children, 2013, the Twelfth Five-Year Plan, Integrated Child Development Services, Matritva Sahyog Yojana, National Health Mission A, SABLA for adolescent girls, Janani Suraksha Yojana, Swachh Bharat including Sanitation and the National Rural Drinking Water Programme, Mahatma Gandhi National Rural Employment Guarantee Scheme and the National Rural Livelihood Mission, Mid-Day Meals Scheme, National Food Security Mission, Targeted Public Distribution System, National Nutrition Mission 2014 and National Nutrition Strategy, 2017, which brought nutrition to the centre stage of the National Development Agenda.

Despite decades of implementation of such programmes addressing the direct causes and fundamental determinants of undernutrition, it is incongruous that India still languishes in the lower rungs of international rankings on child nutrition indicators.

\section{Global nutrition targets}

Appreciating the need for strengthened universal action to confront the widespread challenge of undernutrition, in 2012, WHO chalked out a comprehensive strategy that concentrated on improving maternal, infant and young child nutrition, to be met by 2025 . The targets of reducing the number of stunted children under- 5 by $40 \%$ and reducing childhood wasting to less than $5 \%$, directly address undernutrition among children under-5. The Global Nutrition Report (GNR) 2018 observes that India is likely to fall short of the target, despite some progress made towards reducing child stunting ${ }^{13}$. This is largely because a whopping 46.6 million stunted children or 
$30.9 \%$ of all stunted children under-five - the highest in the world - live in India.

\section{Sustainable Development Goals}

In 2015, 193 Member States of the United Nations (UN) General Assembly adopted a new sustainable development agenda, delineated by 17 Sustainable Development Goals (SDGs) to end poverty, protect the planet and ensure prosperity for all, to be attained by 2030 (ref. 14). The 17 SDGs present a major challenge in terms of scope and scale. While India has made some progress, the improvement is clearly slow-paced and far too little compared to what is envisaged by 2030 . With a score of 48 for SDG 2 on zero hunger and an overall score of 58 for the SDGs, India still carries $23.8 \%$ of the global burden of malnourishment. Nutrition-responsive programmes and nutrition-specific interventions are necessary for creating an enabling environment conducive for the country to meet the SDGs by 2030.

\section{The race to achieve SDG2}

The Government of India (GoI) has continued and focused efforts to improve child and maternal undernutrition in line with SDG2 of zero hunger adopted by the UN. Conscientious implementation of the strong constitutional, policy, plan and programme initiatives already in place at the Centre and State level will accelerate our pace towards achieving the nutritional goals. By attaining successful nutrition outcomes for its population, India would not be just achieving SDG2 but it would be making significant progress in achieving the other 16 SDGs, in effect driving sustainable development as envisaged by the UN. Thus, to attain sustainability in development, it is imperative that we first make headway against undernutrition. Conversely, successful achievement of SDG2, heavily depends on how much progress we make across all the other SDGs, like those aimed at clean water and hygiene, sustainable energy, gender equality and education.

\section{Resolving the conundrum of undernutrition: action}

The following aspects allow us to repose confidence in the Indian public system to achieve targets for reducing child and maternal undernutrition. (1) Elaborate planning and efforts that have been put in place to map the extent of under-5 children and maternal undernutrition ${ }^{15}$. (2) Strong constitutional, policy, plan and programme initiatives taken at the Centre and State level, over the past four decades ${ }^{16}$. (3) The public service system, targeting children under-5, reaches out to children in every village and town in India and is one of a kind in the world. (4) The nutritional data pertaining to each and every child under-5 are available at the Anganwadi level. Surveys by autonomous bodies like the NFHS have generated vast data on multiple dimensions of maternal and child nutrition. NFHS, a series of large-scale surveys conducted in a characteristic sample of households throughout India, under the aegis of the Ministry of Health and Family Welfare, GoI, the latest among which is NHFS-4 (ref. 12), is a multi-round survey. Public service systems should put all the rich data at hand to appropriate and effective use, and develop policies and approaches that benefit every mother and child.

(1) For effective implementation and follow-up on nutrition strategies, information on real-time nutritional status of a child should be readily available. While NFHS reports are released once in a decade, what is essentially required is systematic monitoring on a monthly basis of the growth pattern of every child from birth to 5 years of age, so that attention to their individual nutrition and health needs is ensured.

(2) It has to be made mandatory that information on the weight of children under-5 be gathered from each Anganwadi, and collated at the state level and made available at the Centre for successful coordination and implementation of policy measures. Such a process may prove crucial for improving nutrition outcomes in children under-5.

(3) Data generated on child nutrition status by various state and central agencies are used for policy implementation. Thus, precise growth reporting and reliable data are critical for ensuring continual progress towards achieving child nutrition goals. The key is to identify the fact that undernutrition occurs at specific pockets across states in India. Zeroing down on these areas and reaching out to each underweight or stunted or wasted child through sustained remedial actions alone will yield positive results.

(4) The Government has several supplementary nutrition programmes (SNPs), like the provision of cooked meals for children aged 3-6 years, distribution of takehome rations, supply of nutritious food to pregnant and breastfeeding women, etc. ${ }^{17}$. With the annual budget for implementation of these programmes running into a few thousands of crores of rupees, it has to be ensured that these public funds are optimally utilized for their sole intended purpose.

(5) The facts that up to $60 \%$ of women are anaemic and that about $23 \%$ of women have sub-normal BMI have significant adverse effects on the nutritional status of children ${ }^{18}$. Thus paying attention to maternal nutrition is crucial to improving child nutrition outcomes.

(6) It is vital that nutritional needs of a child in the first thousand days of his/her life are critically met to ensure his/her overall mental and physical growth and intellectual development. The care for the child should start as 
early as the time of its conception by ensuring that the pregnant woman receives optimum levels of nutrition. It has to be ensured that the public health delivery systems operating at the sub-district level, villages, etc. work in close association and record each woman's pregnancy, provide her with the requisite antenatal care, ensure safe delivery and post-natal care for both the mother and the infant until she/he reaches the age of five.

(7) The current percentages of stunting, wasting and underweight prevalent in India have placed the country in an undesirable situation on the global stage. Amending these numbers needs some concerted efforts by the Government, which seems to be on the right track by paying close attention to weight and height figures of a child as a measure of her/his nutritional status. In districts with high incidence of stunting, wasting and underweight among children under-5, weights and heights can be methodically monitored, promptly initiating remedial measures to improve the nutritional status, wherever necessary.

(8) Inept functioning of the government machinery arises from phenomenal concentration of power at the Centre. On the contrary, effective tackling of the undernutrition conundrum requires work to be done at the field-level involving communities, households, families, individuals and caregivers, for which a distinct local initiative is necessary. In addition, centralization of nutrition and health-related operations causes undue delays in the outflow of finances, thus adversely impacting implementation. Empowered local groups are more likely to be successful in getting communities together to manage the issue.

(9) A study by UNICEF revealed that SNPs for children aged 6 months to 6 years, and pregnant and lactating women in Odisha and Uttar Pradesh had suffered from a budget deficit, in spite of adequate national budgetary provision for the year 2019-2020. Such failures in implementation are causes for grave concern. Also, financially sound states like those in the south are likely to allocate adequate funds for nutrition-related programmes, but fiscally deprived states cannot do so. Therefore, suitable attention has to be paid to ensure that funds are made available in regions with high levels of undernutrition.

(10) Public service delivery systems and primary health centres have to be empowered with skilled and dedicated manpower at all levels. Capacity-building measures are needed to enhance the skill-sets and capabilities of workers and supervisors to ensure superior outcomes. The field workers have to be made aware of the importance of height and weight measurements of children for generating reliable data on the levels of stunted, wasted and underweight children.

(11) Positive child nutrition outcomes are vastly dependent on the efforts made by the field-level workers and supervisors functioning at various public service delivery systems. Many of them are responsible for some outstanding work that has resulted in the reduction of child undernutrition levels in their areas. In several instances, they have shown great fervour and resourcefulness in devising innovative methods for changing the lives of children and women under their care for the better. Incentivizing their work and more essentially entrusting financial powers to them for running daily activities will bear exceptional results in the long run. Other aspects that require serious consideration from policy makers is increasing the remuneration paid to the fieldlevel functionaries and regularizing them as government workforce, considering the fact that they contribute immensely in their line of work.

\section{Conclusion}

Despite years of public sector enterprise and initiatives, India still has much to achieve and improve with regards to the nutritional status of its population. Globally, the country performs inadequately across standard child nutritional indices, ranking 102 out of 117 countries for child malnutrition, according to the Global Health Index 2019. For positive nutritional outcomes, it is important to educate mothers and the grassroot-level workers directly responsible for a child's nutritional status, on the importance of the right type and amount of nutrition, encouraging the consumption of foods of diverse calorific value. The midday meal scheme in India, the largest of its kind in the world, is a great opportunity which could be used to strategize and implement micronutrient fortification of foods to address deficiencies prevalent among children. In addition to child undernutrition, the grave consequences of undernutrition among adolescent girls and women have long been recognized, but little quantifiable headway has been made in resolving the distinctive concerns faced by this group. It is crucial for the policymakers to recognize that deprivation in terms of nutrition that adolescent girls and women face can boomerang on the society, resulting in an unhealthy generation of men and women in equal measure. Addressing child and maternal nutrition adequately can place India on the road to achieving the SDGs 1, 2 and 3 of no poverty, zero hunger, and good health and well-being respectively. Improved nutrition holds great significance for the country, as it can lay the foundation for a calm, protected and steady society by becoming the key factor for progress in sectors like health, education, women's empowerment and gender equality.

Conflict of interest: The authors declare that they have no conflict of interest.

This work was undertaken as part of the ongoing ICARCGIAR W3 collaboration in India between ICAR-CIFT, Cochin and World Fish, Malaysia. 
1. Blössner, M. and de Onis, M., Malnutrition: quantifying the health impact at national and local levels. WHO Environmental Burden of Disease Series, No. 12, World Health Organization, Geneva, 2005 .

2. de Onis, M. and Blössner, M., The World Health Organization Global Database on Child Growth and Malnutrition: methodology and applications. Int. J. Epidemiol., 2003, 32, 518-526.

3. FAO, IFAD, UNICEF, WFP and WHO, The state of food security and nutrition in the world 2018. Building climate resilience for food security and nutrition. FAO, Rome, Italy, 2018; License: CC BY-NC-SA 3.0 IGO.

4. Pandey, V., IMF expects India to retain world's fastest growing economy tag. The Economic Times, 2015.

5. von Grebmer, K. et al., Global Hunger Index by Severity: The Challenge of Hunger and Climate Change, Welthungerhilfe, Bonn, Germany and Concern Worldwide, Dublin, Ireland, 2019.

6. Sachdev, Y. and Dasgupta, J., Integrated Child Development Services (ICDS) scheme. Med J., Armed Forces India, 2001, 57, 139143; https://doi.org/10.1016/S0377-1237(01)80135-0

7. United Nations Children's Fund, World Health Organization, International Bank for Reconstruction and Development/The World Bank, Levels and trends in child malnutrition: key findings of the Edition of the Joint Child Malnutrition Estimates, World Health Organization, Geneva, 2019, License: CC BY-NC-SA 3.0 IGO.

8. Chandra, T., Literacy in India: the gender and age dimension. 2019; https://www.orfonline.org/research/literacy-in-india-the-gender-andage-dimension-57150/\# ftn1 (accessed on 19 May 2020).

9. Lindsay, H. A., Anemia and iron deficiency: effects on pregnancy outcomes. Am. J. Clin. Nutrition, 2000, 71, 1280S-1284S.

10. Corsi, D. J., Mejía-Guevara, I. and Subramanian, S. V., Risk factors for chronic undernutrition among children in India: estimating relative importance, population attributable risk and fractions. Soc. Sci. Med., 2016, 157, 165-185.
11. Kshatriya, G. K. and Acharya, S. K., Gender disparities in the prevalence of undernutrition and the higher risk among the young women of Indian tribes. PLOS ONE, 2016, 11, e0158308; https://doi.org/10.1371/journal.pone.0158308

12. IIPS and ICF, National Family Health Survey (NFHS-4), 2015-16. International Institute for Population Sciences, Mumbai, 2017.

13. Development Initiatives, 2018 Global Nutrition Report: shining a light to spur action on nutrition. Development Initiatives, Bristol, UK, 2018.

14. Arora, N. K. and Mishra, I., United Nations Sustainable Development Goals 2030 and environmental sustainability: race against time. Environ. Sustain., 2019, 2, 339-342.

15. Sahu, S. K., Kumar, S. G., Bhat, B. V., Premarajan, K. C., Sarkar, S., Roy, G. and Joseph, N., Malnutrition among under-five children in India and strategies for control. J. Nat. Sci., Biol. Med., 2015, 6, 18-23; https://doi.org/10.4103/0976-9668.149072

16. Banik, D., The hungry nation: food policy and food politics in India. Food Ethics, 2016, 1, 29-45; https://doi.org/10.1007/s41055-0160001-1.

17. Parasar, R. and Bhavani, R. V., Supplementary Nutrition Programme under ICDS: Case study of Telangana and Tamil Nadu. LANSA Working Paper, Leveraging Agriculture for Nutrition in South Asia, Brighton, UK, 2018.

18. Rahman, M. S., Mushfiquee, M., Masud, M. S. and Howlader, T., Association between malnutrition and anemia in under-five children and women of reproductive age: evidence from Bangladesh Demographic and Health Survey 2011. PLoS ONE, 2019, 14, e0219170; https://doi.org/10.1371/journal.pone.0219170

Received 5 June 2020; accepted 6 July 2020

doi: $10.18520 / \mathrm{cs} / \mathrm{v} 119 / \mathrm{i} 4 / 613-617$ 